\title{
Allogeneic Hematopoietic Cell Transplantation After Nonmyeloablative Conditioning
}

\author{
Frédéric Baron \\ Fred Hutchinson Cancer Research Center, Seattle, Washington, U.S.A.
}

\author{
Frederick R. Appelbaum and Brenda M. Sandmaier
}

Fred Hutchinson Cancer Research Center and The University of Washington, Seattle, Washington, U.S.A.

\section{INTRODUCTION}

High-dose chemo- or chemoradiotherapy followed by allogeneic hematopoietic cell transplantation (HCT) has been recognized as an effective therapy for a number of hematologic malignancies with tumor cells resistant to conventional doses of chemotherapy (1). The aims of the high-dose conditioning are (i) to abolish host immune responsiveness prior to transplantation to avoid graft rejection and (ii) to deliver doses of cytotoxic anticancer agents beyond the range that is toxic to the bone marrow cells, thereby potentially increasing antitumor efficacy (1). The curative potential of allogeneic HCT is not only due to the high-dose chemoradiotherapy but also due to immune-mediated graft-versus-tumor (GVT) effects (2-4).

The existence of a GVT effect was first suggested by Barnes et al. in 1956 (5). They observed that mice receiving syngeneic HCT and injection of congenic leukemic cells after total body irradiation (TBI) almost uniformly died from 
leukemia, whereas a number of mice receiving histoincompatible marrow were cured of leukemia but eventually died from the graft-versus-host disease (GVHD). The authors suggested that a reaction of the donor spleen cells might kill cancer cells. This hypothesis was evinced two decades later in humans by studies reporting reduced leukemic relapse rates in allografted patients who developed GVHD compared with those who did not $(2,3)$. The GVT effect was further demonstrated by other investigators who observed increased risks of relapse in patients given T-cell-depleted grafts and in recipients of syngeneic transplants (3).

Those observations led several groups of investigators to investigate the curative potential of donor lymphocytes infusions (DLI) in patients who had relapsed after allogeneic HCT (4). Two large multicenter studies, one from the European Group for Blood and Marrow Transplantation (EBMT) (4) and the other from North America (6), have analyzed the efficacy of DLI in more than 400 patients (Table 1). DLI induced complete remissions in more than $60 \%$ of patients with chronic myeloid leukemia and $10 \%$ to $40 \%$ of patients with other hematologic malignancies. Typically, achievement of complete remissions required several weeks. For example, an average time of four to six months was required before molecular remission was achieved in patients with relapsed chronic myeloid leukemia (4). While $50 \%$ of patients without acute GVHD showed tumor regression, this increased to $75 \%$ and $85 \%$ in patients with grade I or grades II to IV acute GVHD, respectively (4). Similarly, chronic GVHD was associated with disease responses (4,6). DLI have been given without any other treatment in patients with indolent disease such as chronic myeloid leukemia in chronic phase, while chemotherapy has been given before DLI in a number of

Table 1 Results of Donor Lymphocyte Infusions as Treatment of Relapse After HLAMatched HCT Following Myeloablative Conditioning

\begin{tabular}{lcc}
\hline & $\begin{array}{l}\text { North America (6) } \\
\text { Complete response/ } \\
\text { evaluable patients (\%) }\end{array}$ & $\begin{array}{l}\text { EBMT (4) } \\
\text { Complete response/ } \\
\text { evaluable patients (\%) }\end{array}$ \\
\hline Chronic myeloid leukemia & & $40 / 50(80)$ \\
$\quad$ Cytogenetic/molecular relapse & $3 / 3(100)$ & $88 / 114(77)$ \\
$\quad$ Hematologic relapse & $25 / 34(74)$ & $13 / 36(36)$ \\
$\quad$ Accelerated phase/blast crisis & $5 / 18(28)$ & $16 / 59(27)$ \\
Acute myeloid leukemia/ & $8 / 44(18)$ & $3 / 20(15)$ \\
myelodysplastic syndrome/ & & $5 / 17(29)$ \\
polycythemia vera & $2 / 11(18)$ & - \\
Acute lymphoblastic leukemia & $2 / 4(50)$ & \\
Multiple myeloma & $0 / 6(0)$ & \\
Non-Hodgkin's lymphoma & &
\end{tabular}

Abbreviation: EBMT, European Group for Blood and Marrow Transplantation. 
89

90

91

92

93

94

95

96

97

98

99

100

101

102

103

104

105

106

107

108

109

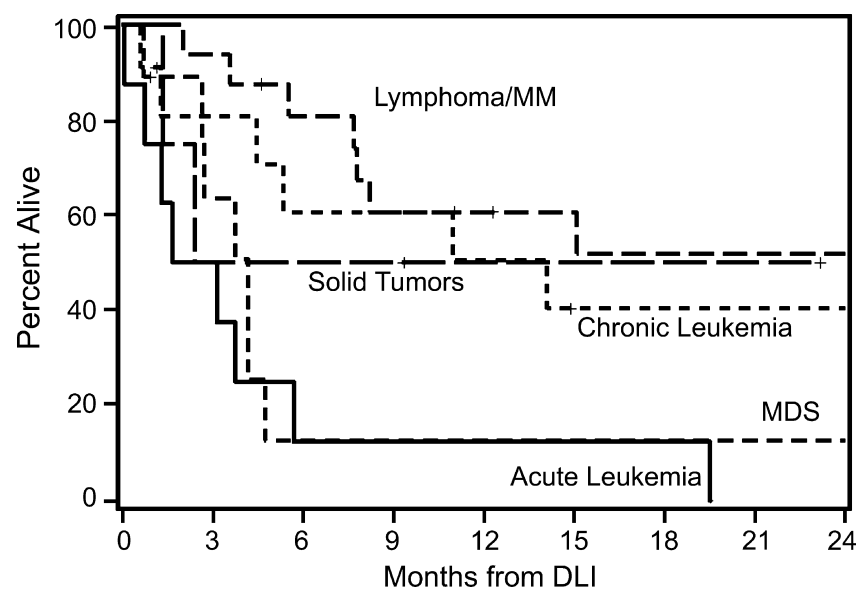

Figure 1 Diagnosis and survival after DLI given for progressive disease/relapse after nonmyeloablative HCT. Kaplan-Meier plots of survival after DLI depending on diagnoses. Survival estimates at one year were $61 \%$ for B-cell malignancies, $51 \%$ for chronic leukemia, $50 \%$ for solid tumors, $13 \%$ for acute leukemia, and again $13 \%$ for myelodysplastic syndrome, respectively. Source: From Ref. 7.

patients with more aggressive diseases. Figure 1 shows overall survival in 48 patients given DLI for progressive disease/relapse after nonmyeloablative conditioning (7).

Because of regimen-related toxicities, the use of high-dose myeloablative conditionings has been restricted to younger and medically fit patients. This is unfortunate, given that the median age at diagnosis of patients with acute and chronic myeloid leukemias, chronic lymphocytic leukemia, non-Hodgkin's lymphomas (NHLs), myelodysplastic syndromes, and multiple myeloma ranges from 65 to 70 years (1). In 1971, Santos et al. reported that conditioning with cyclophosphamide alone, although nonmyeloablative enabled sustained engraftment of transplanted allogeneic hematopoietic cells in patients with advanced leukemia (8). Unfortunately, tumor cells were not completely eradicated, and all patients eventually relapsed. While cyclophosphamide became the conditioning regimen of choice for patients with aplastic anemia (1), it was abandoned as the sole conditioning regimen in patients with hematologic malignancies. In 1974, Graw et al. reported a few cures in patients with acute leukemia given allogeneic marrows after a reduced-intensity (9) conditioning regimen combining BCNU, cytarabine, cyclophosphamide, and thioguanine (10). The growing evidence of the power of GVT effects, as demonstrated by the efficacy of DLI, incited several groups of investigators to develop new reducedintensity (11-14) or truly nonmyeloablative conditioning regimens (15-17) allowing older patients and those with comorbidities to benefit from GVT effects (Table 2). 
133

134

135

136

137

138

139

140

141

142

143

144

145

146

147

148

149

150

151

152

153

154

155

156

157

158

159

160

161

162

163

164

165

166

167

168

169

170

171

172

173

174

175

176

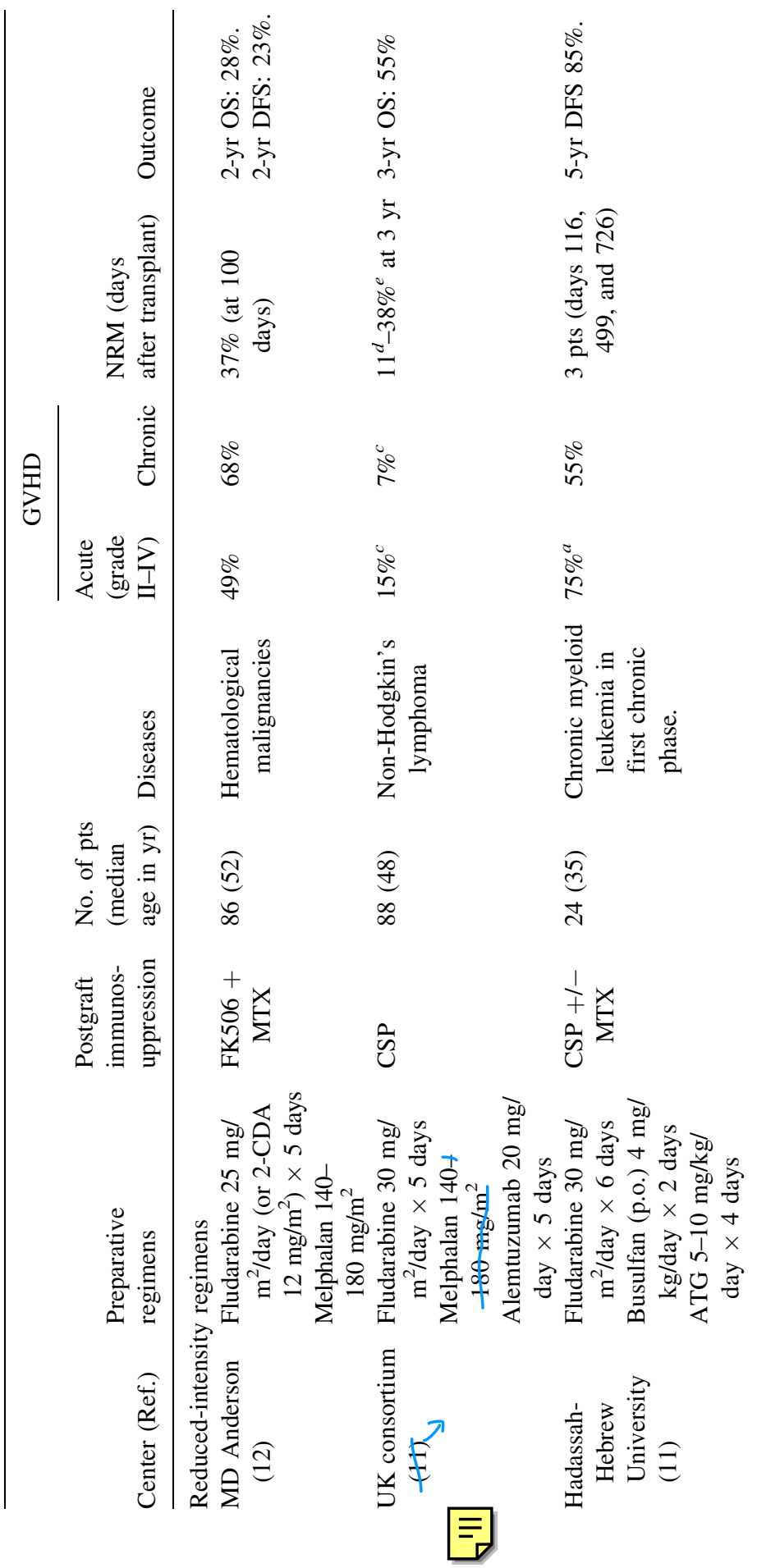


$\frac{d}{8} \frac{\pi}{8}$

$\cdot \vec{D} \overline{\mathrm{I}}$

179

180

结造

181

도

182

त $\mathrm{N}$

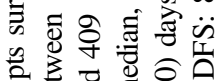

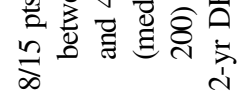

183

184

185

186

187

188

189

190

191

192

193

194

195

196

197

198

199

200

201

202

203

204

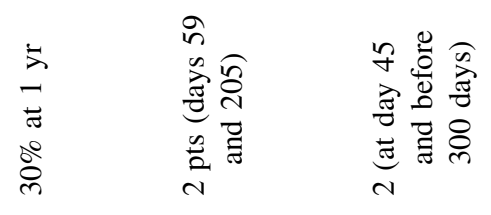

205

206

207

208

is z

209

210

211

212

213

214

215

216

217

218

219

220
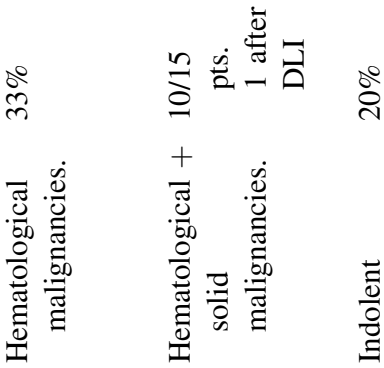

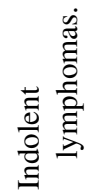

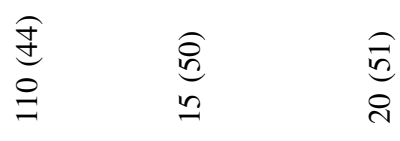

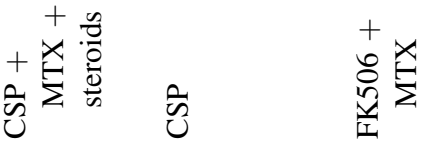

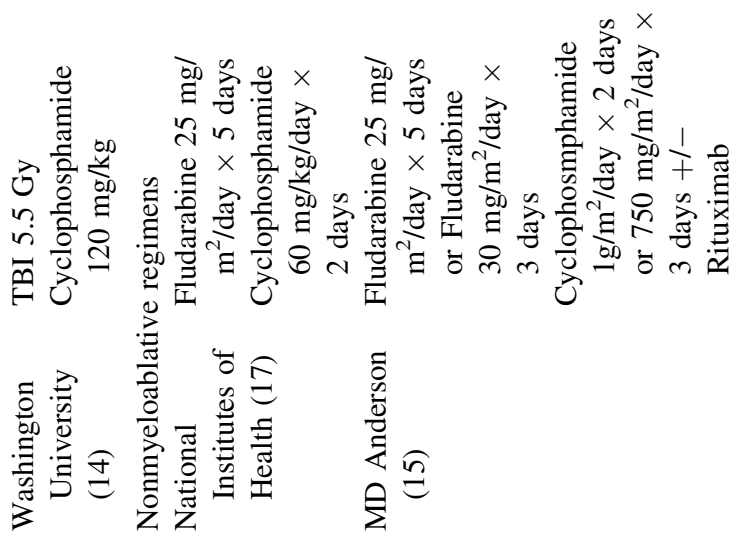


221

222

223

224

225

226

227

228

229

230

231

232

233

234

235

236

237

238

239

240

241

242

243

244

245

246

247

248

249

250

251

252

253

254

255

256

257

258

259

260

261

262

263

264

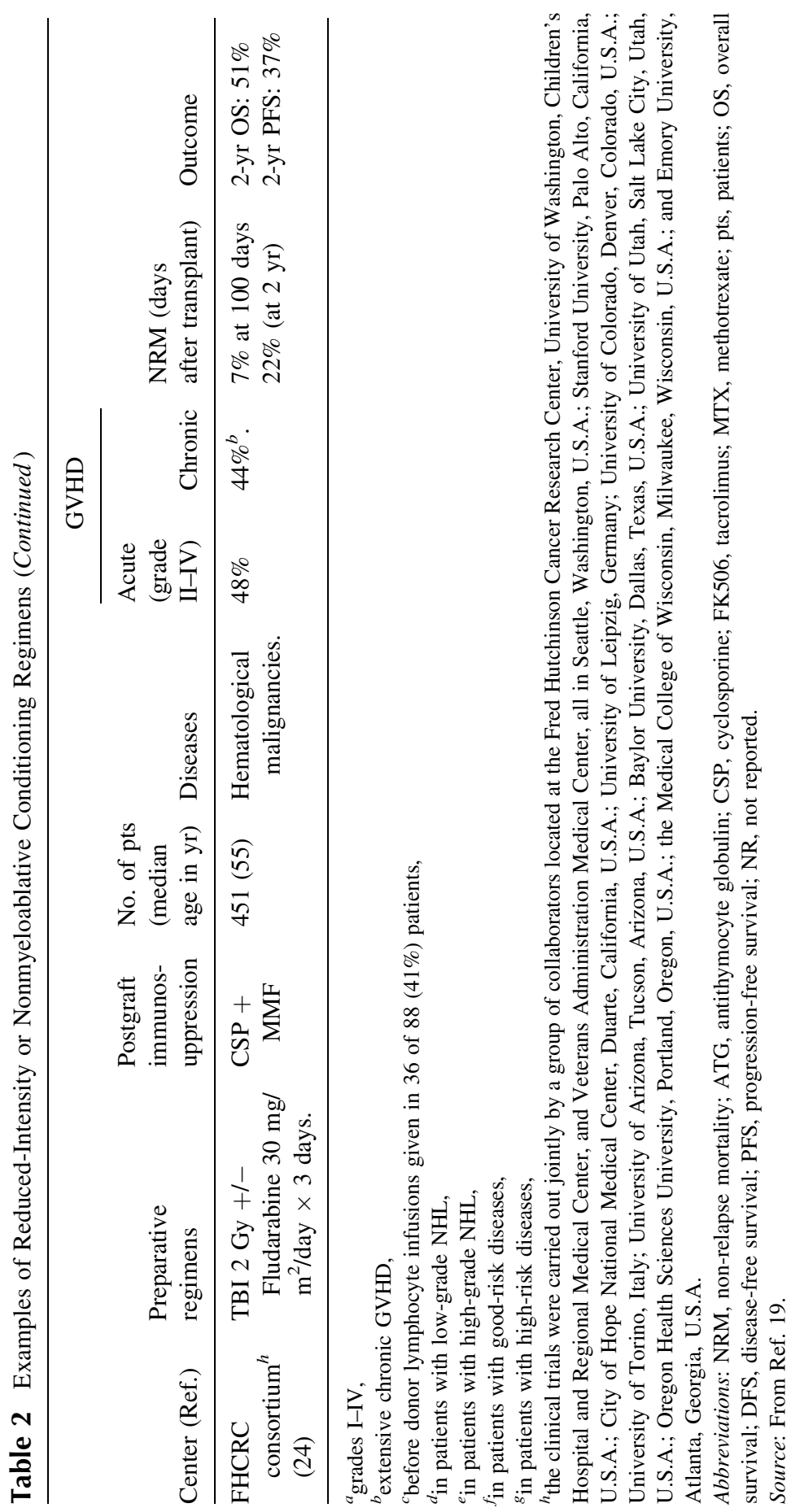




\section{NONMYELOABLATIVE OR REDUCED-INTENSITY REGIMENS}

Many of the reduced-intensity conditioning regimens do not meet criteria of nonmyeloablative conditioning as first proposed by Champlin et al., which include (i) no eradication of host hematopoiesis, (ii) prompt hematologic revovery ( $<4$ weeks) without transplant, and (iii) presence of mixed chimerism upon engraftment $(18,19)$. Most reduced-intensity conditioning regimens combine modest dose of highly immunosuppressive purine analogs (fludarabine, cladribine, or pentostatin) given to overcome host-versus-graft reactions, with reasonably high-dose of alkylating agents, usually busulfan or melphalan, given to supplement the GVT effects in the task of tumor eradication. Conversely, nonmyeloablative conditioning regimens usually combine two highly immunosuppressive agents together (low-dose TBI, fludarabine, or cyclophosphamide) to overcome host-versus-graft reactions to allow engraftment and tumor eradication via GVT effects $(16,20)$. Although the division of what constitutes a nonmyeloablative versus reduced-intensity conditioning regimen is somewhat arbitrary, the distinction might be important, given that nonmyeloablative conditioning has been associated with a lower degree of donor engraftment, decreased risk of nonrelapse mortality, and perhaps higher risk of relapse in comparison with reduced-intensity regimens (21).

\section{NONMYELOABLATIVE CONDITIONING WITH 2 GY TBI AND FLUDARABINE}

On the basis of preclinical studies in a canine model (22), we developed a nonmyeloablative conditioning regimen for allogeneic HCT consisting of 2 Gy TBI given on day 0 , with postgrafting immunosuppression combining mycophenolate mofetil (MMF) and cyclosporin (CSP) (16). Nine of the first 44 patients $(20 \%$, including four of eight patients with chronic myeloid leukemia) given this regimen had nonfatal graft rejections $(16,23)$. In order to reduce the risk of graft rejection, fludarabine $30 \mathrm{mg} / \mathrm{m}^{2} /$ day $\times 3$ days was added to the 2 Gy TBI, and the rejection rate decreased to $3 \%$ (24). The same nonmyeloablative regimen combining fludarabine and 2 Gy TBI was used to condition patients with 10/10-human leukocyte antigen (HLA)-matched unrelated donors (25). Sustained engraftment was observed in 60 of $71(85 \%)$ peripheral blood stem cells (PBSC) recipients and in 10 of $18(56 \%)$ marrow recipients. On the basis of this observation, all subsequent unrelated recipients were given PBSC grafts. Analysis of the first 451 patients with hematologic malignancies transplanted in a multicenter international consortium is shown in Table 1 (24). Median patient age was 55 (range, 5-74) years, and median follow-up was 696 (range, 82-1795) days. All patients were deemed ineligible for myeloablative conditioning because of age and/or comorbidities. Diagnoses included multiple myeloma $(n=114)$, myelodysplastic syndromes or myeloproliferative disorders $(n=82)$, NHLs $(n=79)$, acute myeloid leukemia $(n=59)$, chronic lymphocytic leukemia 
( $n=44)$, chronic myeloid leukemia $(n=37)$, Hodgkin's disease $(n=26)$, and acute lymphoblastic leukemia $(n=10)$. Three hundred and thirty-two patients had measurable disease at transplantation, and $56.5 \%$ achieved complete $(49 \%)$ or partial $(7.5 \%)$ remissions. The incidences of nonrelapse mortality at 100 days and two years were $7 \%$ and $22 \%$, respectively. Main causes of nonrelapse mortality were GVHD and infections. The two-year probabilities of overall and progression-free survivals were $51 \%$ and $37 \%$, respectively.

\section{KINETICS OF DONOR ENGRAFTMENT AFTER NONMYELOABLATIVE CONDITIONING}

The engraftment kinetics after nonmyeloablative conditioning regimen were first analyzed by Childs et al. (17). The authors studied chimerism (i.e., proportion of hematopoietic cells of donor origin) evolution in 15 patients conditioned with fludarabine $\left(125 \mathrm{mg} / \mathrm{m}^{2}\right)$ and cyclophosphamide $(120 \mathrm{mg} / \mathrm{kg})$. The patterns of engraftment varied between patients, but most often, full donor chimerism was achieved earlier among T-cells than among granulocytes, and achievement of full donor T-cell chimerism preceded GVHD and antitumor responses. Conversely, Ueno et al. studied chimerism evolution in 23 patients with metastatic tumors transplanted after conditioning with fludarabine $\left(125-150 \mathrm{mg} / \mathrm{m}^{2}\right)$ and melphalan $\left(140 \mathrm{mg} / \mathrm{m}^{2}\right)(26)$. All patients had full donor T-cell and granulocyte chimerisms by day 30 after HCT.

We analyzed the kinetics of donor engraftment in various peripheral blood hematopoietic subpopulations from 120 patients conditioned with 2 Gy TBI $+/$ - fludarabine and postgrafting immunosuppression with MMF and CSP (27). On day 14 post transplant, the highest degree of donor chimerism was seen in the NK cells followed by T-cells, monocytes, and granulocytes (Fig. 2A). By day 28, donor granulocyte chimerism had surpassed those in the remaining cell populations. PBSC recipients had higher degrees of donor $\mathrm{T}$-cell chimerism than recipients of marrow, while greater intensity of therapy before HCT was associated with higher degrees of donor chimerisms. Day-14 donor chimerism levels less than 50\% among T-cells $(p=0.0007)$ and NK cells $(p=0.003$ ) predicted graft rejection (Fig. 2B). High donor chimerism levels on day 14 among T-cells were associated with increased risks of grades II to IV acute GVHD $(p=0.02)$, while high donor T-cell $(p=0.002)$ and NK cell $(p=0.002)$ chimerism levels from days 14 to 42 were associated with decreased risks of relapse. In addition, high levels of donor NK cell chimerism early after HCT correlated with better progression-free survival $(p=0.02)$ and a trend for better overall survival $(p=0.09)$.

These observations suggest that assessing donor chimerism levels among T-cells and NK cells might help identify patients at risk for graft rejection, acute GVHD, and relapse, and thereby allow early interventions with DLI and/or immunosuppressive drugs $(7,28)$. 
(A)

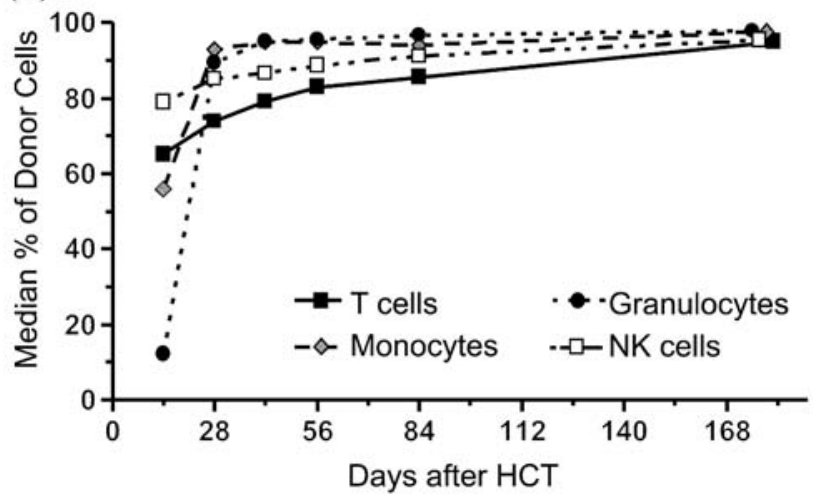

(B)

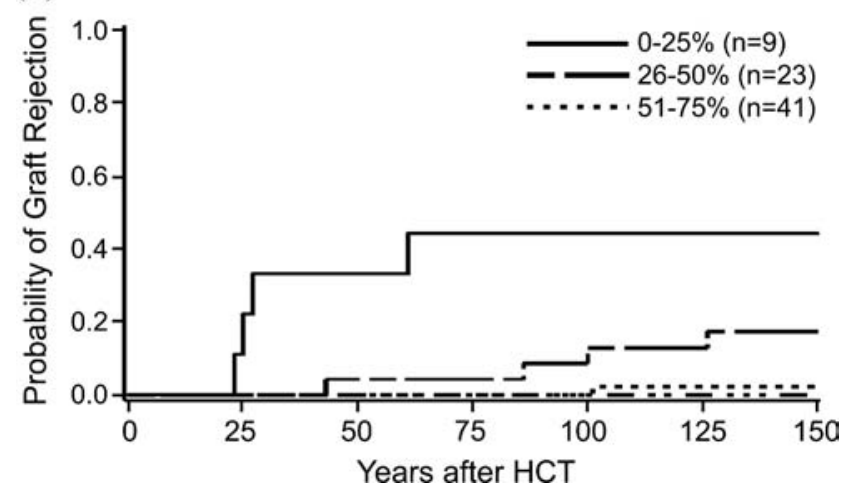

Figure 2 (A) Engraftment kinetics after nonmyeloablative conditioning in 108 patients who achieved sustained engraftment. (B) Cumulative incidence of graft rejection according to day-14 T-cell chimerism. Source: From Ref. 27.

\section{GVHD AND GVT EFFECTS AFTER NONMYELOABLATIVE CONDITIONING}

GVHD remains a major cause of morbidity and mortality after nonmyeloablative or reduced-intensity conditioning (16,25). Mielcarek et al. compared GVHD in 52 patients given myeloablative conditioning with that among 44 patients given nonmyeloablative conditioning (29). Recipients in both groups were age matched, with median ages of 54 years in the myeloablative and 56 years in the nonmyeloablative groups. Grafts were from either related or unrelated donors who were serologically matched for HLA-A, -B, and -C and allele level matched for HLA-DRB1 and -DQB1. Postgrafting immunosuppression consisted of methotrexate (MTX) plus CSP $(n=45)$ or MMF plus CSP $(n=7)$ in myeloablative 
recipients, versus MMF plus CSP in all nonmyeloablative recipients. The cumulative incidences of grades II to IV acute GVHD were $85 \%$ in myeloablative recipients versus $64 \%$ in nonmyeloablative recipients $(p=0.001)$, but there were no differences in the cumulative incidences of extensive chronic GVHD (71\% vs. $73 \%$, respectively). The 15-month cumulative incidences of death with manifestations of GVHD under treatment were $35 \%$ and $24 \%$ in myeloablative and nonmyeloablative recipients, respectively (NS).

Although there is a close relationship between GVHD and GVT responses observed after myeloablative HCT $(2-4,6)$, whether some degree of clinical GVHD was required for accomplishing remissions after nonmyeloablative conditioning was less clear. In order to address this question, we analyzed the impact of either acute or chronic GVHD on HCT outcomes in 322 patients with hematologic malignancies given grafts from HLA-matched related $(n=192)$ or unrelated $(n=130)$ donors following conditioning with 2 Gy TBI with or without fludarabine $\left(90 \mathrm{mg} / \mathrm{m}^{2}\right)$ (20). Two hundred and twenty-one patients had measurable malignant disease at the time of transplantation, and 126 of them $(57 \%)$ achieved complete $(n=98)$ or partial $(n=28)$ remissions 27 to 963 days (median, 176 days) after HCT. Extensive chronic GVHD was suggestively associated with a higher probability of achieving complete remissions (HR 1.7, $p=0.07$ ), but no associations between acute GVHD and achievement of complete remissions were seen. Grades II and III to IV acute GVHD did not decrease the risks of progression/relapse but were associated with an increased risk of nonrelapse mortality and decreased progression-free survival. In contrast, extensive chronic GVHD was associated with decreased risk of progression/ relapse (HR 0.4, $p=0.006$ ) and better progression-free survival (HR 0.5, $p=0.003$ ) (Fig. 3). The beneficial impact of chronic GVHD on relapse was seen in all disease groups but was strongest in the group of patients with acute myeloid leukemia or myelodysplastic syndrome (HR $0.2, p=0.0009$ ).

Similarly, a number of other recent reports have shown a negative impact of grades II to IV acute GVHD $(30,31)$ but a beneficial impact of chronic GVHD $(31,32)$ on HCT outcomes in patients given HCT after reduced-intensity or nonmyeloablative conditioning.

Some reduced-intensity conditioning regimens have used in vivo T-cell depletion of the grafts [with either antithymocyte globulin (ATG) or alemtuzumab] to decrease the incidence of GVHD. While these strategies achieved their goal $(11,13)$, increased incidences of both infections and disease relapses were observed, resulting in comparable progression-free survival.

\section{TOXICITIES AFTER MYELOABLATIVE OR NONMYELOABLATIVE CONDITIONING}

A number of retrospective studies have compared incidences of toxicity and infection after nonmyeloablative versus myeloablative conditioning (Table 3) (33-37). Nonmyeloablative conditioning was associated with decreased 


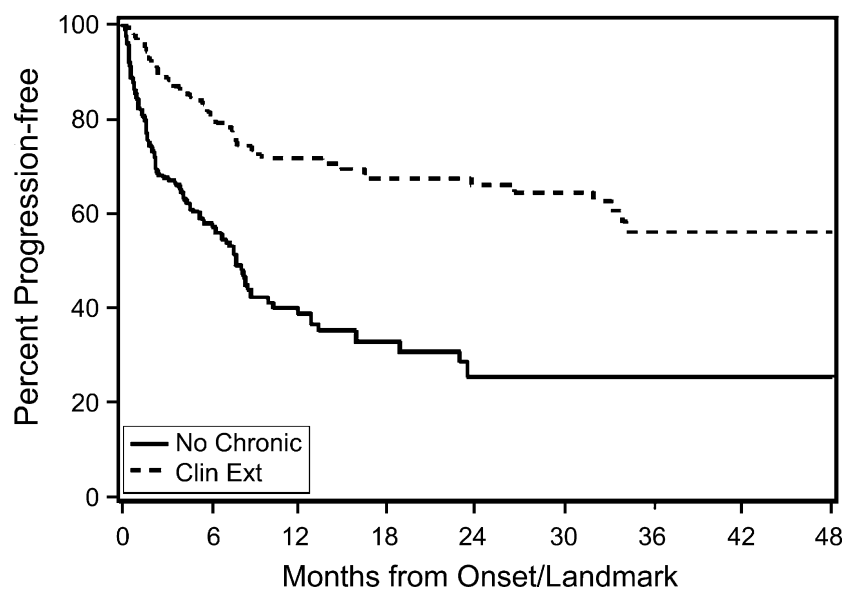

Figure 3 Semilandmark plots illustrating progression-free survival among patients with and without extensive chronic GVHD (20). For patients diagnosed with extensive chronic GVHD, survival is plotted as a function of time since onset of GVHD. For patients free of disease progression and without a diagnosis of extensive chronic GVHD at day 135 (the median day of onset for those with extensive chronic GVHD), survival is plotted as a function of time since day 135. For this group the survival is the conditional survival among patients remaining without a diagnosis of extensive chronic GVHD. Abbreviation: GVHD, graft-versus-host disease. Source: From Ref. 20.

transfusion requirements (33), decreased incidence of idiopathic pneumonia syndrome (IPS) (34), decreased incidence of sinusoidal obstruction syndrome (SOS) (35), decreased incidence of acute renal failure (38), and decreased incidence of bacterial and cytomegalovirus (CMV) infections early after HCT $(36,37)$. However, overall CMV reactivations and fungal infections were similarly frequent after nonmyeloablative and myeloablative conditioning $(36,37)$.

Sorror et al. analyzed transplantation-related toxicities (graded according to the National Cancer Institute common toxicity criteria) following HLA-matched unrelated HCT in 134 concurrent patients given either nonmyeloablative $(n=60)$ or myeloablative $(n=74)$ conditioning (39). Additionally, the effects of pretransplant comorbidities [graded according to the Charlson Comorbidity Index (CCI) score] on outcome were investigated. Lower numbers of gastrointestinal $(p<0.0001)$, hepatic $(p=0.005)$, hematologic $(p<0.0001)$, infection-related $(p=0.02)$, and hemorrhagic $(p=0.02)$ grades III to IV toxicities were seen in nonmyeloablative compared with myeloablative recipients, whereas incidences of cardiovascular, metabolic, pulmonary, and renal toxicities were not statistically significantly different between the two groups. The one-year nonrelapse mortality was $32 \%$ in patients given myeloablative conditioning compared with $20 \%$ in patients given nonmyeloablative conditioning. In multivariate analyses adjusting for disease risk, age, and CCI score at HCT, myeloablative conditioning was 
Table 3 Toxicity After Nonmyeloablative (Consisting of 2 Gy Total Body Irradiation with or Without $90 \mathrm{mg} / \mathrm{m}^{2}$ Fludarabine) Vs. Myeloablative Conditioning Regimens

\begin{tabular}{|c|c|c|c|}
\hline Toxicity (Refs.) & Nonmyeloablative & Myeloablative & $p$ value \\
\hline \multicolumn{4}{|c|}{ Hematological Toxicity (transfusion requirements) (33) } \\
\hline Median units red cells & $2(0-50)$ & $6(0-34)$ & $p=0.0002$ \\
\hline Median units platelets & $0(0-214)$ & $24(4-358)$ & $p<0.0001$ \\
\hline \multicolumn{4}{|l|}{ Pulmonary Toxicity (34) } \\
\hline 120-day CI of IPS & $2.2 \%$ & $8.4 \%$ & $p=0.003$ \\
\hline \multicolumn{4}{|l|}{ Hepatic Toxicity $(35,40)$} \\
\hline $\begin{array}{l}\text { 200-day CI of } \\
\text { hyperbilirubinemia }^{a}\end{array}$ & $26 \%$ & $48 \%$ & ND \\
\hline $\begin{array}{l}\text { 100-day CI of sinusoidal } \\
\text { obstructive syndrome }\end{array}$ & $0 \%$ & $18 \%$ & ND \\
\hline \multicolumn{4}{|l|}{ Renal toxicity (38) } \\
\hline $\begin{array}{l}\text { 100-day CI of grades II-III } \\
\text { acute renal failure }\end{array}$ & $47 \%$ & $73 \%$ & $p<0.0001$ \\
\hline 100-day CI of dialysis & $3 \%$ & $12 \%$ & $p<0.0001$ \\
\hline \multicolumn{4}{|l|}{ Infections $(36,37)$} \\
\hline $\begin{array}{l}\text { 30-day CI of bacterial } \\
\text { infection }\end{array}$ & $9 \%$ & $27 \%$ & $p=0.01$ \\
\hline $\begin{array}{l}\text { 100-day CI of bacterial } \\
\text { infection }\end{array}$ & $27 \%$ & $41 \%$ & $p=0.07$ \\
\hline 1-yr CI of aspergillosis & $14 \%$ & $10 \%$ & $p=0.30$ \\
\hline 100-day CI of CMV disease & $6 \%$ & $19 \%$ & $p=0.06$ \\
\hline 1-yr CI of CMV disease & $24 \%$ & $25 \%$ & $p=0.87$ \\
\hline \multicolumn{4}{|l|}{ GVHD (29) } \\
\hline \multicolumn{4}{|l|}{$\begin{array}{l}\text { 100-day CI of grades II-IV } \\
\text { acute GVHD }\end{array}$} \\
\hline Matched siblings & $62 \%$ & $77 \%$ & $p=0.02$ \\
\hline Matched unrelated donors & $65 \%$ & $95 \%$ & $p=0.01$ \\
\hline \multicolumn{4}{|l|}{ CI of extensive chronic } \\
\hline Matched siblings & $77 \%$ & $74 \%$ & $p=0.37$ \\
\hline Matched unrelated donors & $68 \%$ & $69 \%$ & $p=0.37$ \\
\hline Mortality from GVHD & $24 \%$ & $35 \%$ & $p=0.07$ \\
\hline
\end{tabular}

${ }^{a} 4 \mathrm{mg} / \mathrm{dL}$.

Abbreviations: CI, cumulative incidence; IPS, idiopathic pneumonia syndrome; ARF, acute renal

associated with increased risks of grade IV toxicities (HR 9.4, $p=0.0001$ ) and higher one-year nonrelapse mortality (HR 3.0, $p=0.04$ ). Interestingly, higher pretransplant CCI scores predicted for increased mortality. Comparable results were observed by Diaconescu et al. in patients given grafts from HLA-identical sibling donors (40). 


\section{RELAPSE AND SURVIVAL AFTER MYELOABLATIVE OR NONMYELOABLATIVE CONDITIONING}

531

532

533

534

535

536

537

538

539

540

541

542

543

544

545

546

547

548

549

550

551

552

553

554

555

556

557

558

559

560

561

562

563

564

565

566

567

568

569

570

571

572

It has remained difficult to compare relapse risk and survival after myeloablative versus nonmyeloablative recipients, given the short follow-up (and relatively low number) of patients given HCT after nonmyeloablative conditioning so far and the fact that nonmyeloablative recipients were generally older and had more comorbidities than patients given myeloablative conditioning. Two randomized studies in the early 1990s demonstrated lower risk of relapse, increased nonrelapse mortality, and similar survival in patients treated with cyclophosphamide and 15.5 Gy versus 12 Gy TBI followed by HLA-identical sibling HCT, demonstrating that dose intensity does matter for both toxicity and antitumor efficacy $(41,42)$.

Alyea et al. performed a retrospective analysis of 152 patients $(>50$ years old) with hematologic malignancies undergoing HCT after myeloablative [mainly cyclophosphamide $\left(3.6 \mathrm{~g} / \mathrm{m}^{2}\right)$ and TBI $(14 \mathrm{~Gy})$ ] or reduced-intensity conditioning combining fludarabine $\left(120 \mathrm{mg} / \mathrm{m}^{2}\right)$ and intravenous busulfan $(3.2 \mathrm{mg} / \mathrm{kg}$ ) (43). Patients given nonmyeloablative conditioning were more likely to receive grafts from unrelated donors (58\% vs. $36 \%, p=0.009)$, to have received a prior HCT $(25 \%$ vs. $4 \%, p<0.0001)$, and to have active disease at the time of transplantation ( $85 \%$ vs. $59 \%, p<0.001)$. With a median follow-up of 18 months, the cumulative incidences of relapse and nonrelapse mortality were $46 \%$ and $32 \%$ in the reduced-intensity conditioning group, versus $30 \%$ and $50 \%$, respectively, in the myeloablative group. Two-year overall survival was perhaps superior in the nonmyeloablative group (39\% vs. $29 \% ; p=0.056)$.

\section{RESULTS IN SPECIFIC DISEASES}

\section{Acute Myeloid Leukemia and Myelodysplastic Syndrome}

Hegenbart et al. analyzed outcome of 122 patients with acute myeloid leukemia ineligible for conventional HCT given allogeneic grafts after 2 Gy TBI with or without added fludarabine $\left(90 \mathrm{mg} / \mathrm{m}^{2}\right)$, and postgrafting immunosuppression combining MMF and CSP (44). Two-year probabilities of overall survival were $51 \%$ for patients transplanted in first complete remission $(n=51), 61 \%$ for those transplanted in second remission $(n=39)$, and $28 \%$ for those transplanted beyond second remission $(n=32)$ (Fig. 4). High cytogenetic risks predicted for decreased overall survival (HR 2.4, $p=0.008$ ).

Using a genetic randomization through a "donor" versus "no donor" comparison, Mohty et al. investigated whether allogeneic HCT after conditioning with fludarabine $\left(180 \mathrm{mg} / \mathrm{m}^{2}\right)$, busulfan $(8 \mathrm{mg} / \mathrm{kg})$, and ATG increased survival in adults (median age 52 years) with newly diagnosed high-risk acute myeloid leukemia in first complete remission ineligible for conventional HCT (45). Ninetyfive patients were retrospectively analyzed; 35 had an HLA-identical sibling donor (donor group), while 60 had no related HLA-matched donor (no donor group). 
573

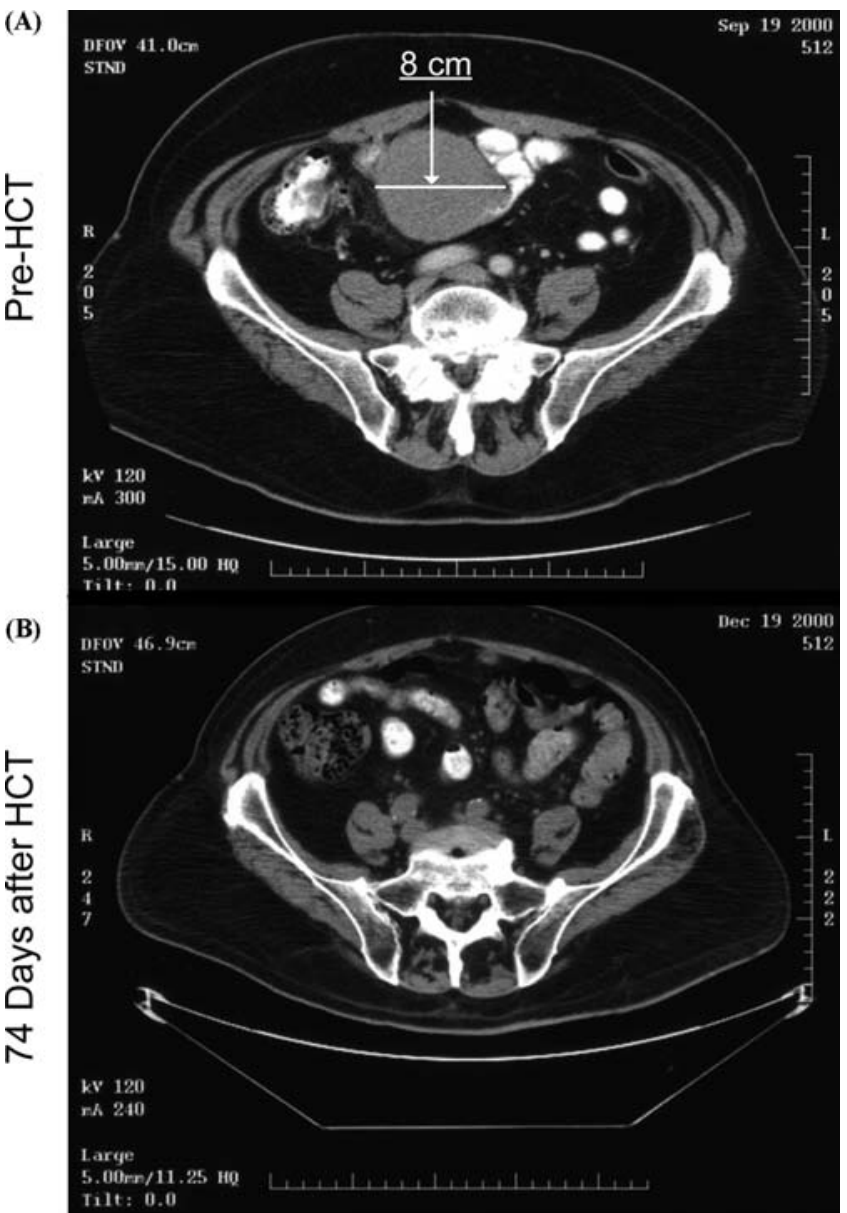

Figure 4 Example of GVT response in a patient with mantle cell lymphoma relapsing after high-dose radiolabeled antibodies with autologous peripheral blood stem cell support. (A) Pretransplantation CT scan image (day 27) through the upper pelvis demonstrating an $8-\mathrm{cm}$ by $7-\mathrm{cm}$ mass that extended through $120.5-\mathrm{cm}$ cuts. (B) CT scan image through the same region demonstrating complete resolution of the mass on day +74 after nonmyeloablative transplantation from a matched unrelated donor. The patient remains in remission 30 months after transplantation with no evidence of GVHD. Abbreviations: GVT, graft-versus-tumor; CT, computed tomography; GVHD, graft-versus-host disease. Source: From Ref. 50.

Twenty-five of thirty-five patients included in the donor group (71\%) received allogeneic HCT. The 10 remaining patients with an identified donor did not receive allogeneic HCT because of patient or donor refusal $(n=6)$, early relapse $(n=2)$, or psychiatric disorders appearing before HCT $(n=2)$. In an intention to 
treat analysis, the four-year probability of progression-free survivals was $54 \%$ in the donor group versus $30 \%$ in the nondonor group ( $p=0.01$ ).

Ho et al. analyzed data from 62 patients with myelodysplastic syndrome given allografts from related $(n=24)$ or unrelated $(n=38)$ donors after reducedintensity conditioning with fludarabine $\left(150 \mathrm{mg} / \mathrm{m}^{2}\right)$, oral busulfan $(8 \mathrm{mg} / \mathrm{kg})$, and alemtuzumab (100 mg total dose) (46). Postgrafting immunosuppression consisted of CSP alone. Median patient age at HCT was 56 years for patients given grafts from siblings and 52 years for patients given grafts from unrelated donors. Sixteen patients had refractory anemia, 19 refractory anemia with blast excess, 23 refractory anemia with blast excess in transformation, and 4 chronic myelomonocytic leukemia. The one-year probabilities of nonrelapse mortality, overall survival, and progression-free survival were $5 \%, 73 \%$, and $61 \%$, respectively, for patients given grafts from related donors versus $21 \%, 71 \%$, and $59 \%$, respectively, for patients given grafts from unrelated donors.

\section{Chronic Myeloid Leukemia}

Or et al. reported data from 24 patients (median age 35 years) with chronic myeloid leukemia in first chronic phase given HLA-matched related $(n=19)$ or unrelated $(n=5)$ grafts after reduced-intensity conditioning combining fludarabine $\left(180 \mathrm{mg} / \mathrm{m}^{2}\right)$, busulfan $(8 \mathrm{mg} / \mathrm{kg})$, and ATG (11). Day-100 mortality was $0 \%$, but three patients died as a consequence of GVHD 116, 499, and 726 days after HCT. The five-year probability of progression-free survival was $85 \%$, with all 21 survivors having negative reverse transcriptase-polymerase chain reaction (RT-PCR) for Bcr-Abl.

Kerbauy et al. analyzed data from 24 patients (median age 58 years) with chronic myeloid leukemia in first chronic phase $(n=14)$ or beyond $(n=10)$ given PBSC from HLA-matched related donors after conditioning with 2 Gy TBI with $(n=16)$ or without $(n=8)$ fludarabine $(23)$. Four of eight patients not given fludarabine experienced nonfatal graft rejection and recurrence of chronic myeloid leukemia, while the 20 remaining patients achieved sustained engraftment. The two-year overall survival rate was $70 \%$ for patients transplanted in first chronic phase, and $56 \%$ for those with more advanced disease. Nine of ten patients transplanted in first chronic phase after conditioning with 2 Gy TBI with fludarabine achieved molecular remissions 3 to 24 months after HCT.

In contrast to what was observed in patients given grafts from HLAmatched sibling donors, a high rate of graft rejection among chronic myeloid leukemia patients receiving grafts from unrelated donors after nonmyeloablative or reduced-intensity conditioning has been reported. We observed graft rejection in 9 of 21 patients given unrelated grafts for chronic myeloid leukemia after 2 Gy TBI and fludarabine (47). Graft rejections were nonfatal in all cases and followed by autologous reconstitution with persistence or recurrence of chronic myeloid leukemia. Seven of eleven patients with sustained engraftment, including all five patients in first chronic phase were alive in complete 
661

662

663

664

665

666

667

668

669

670

671

672

673

674

675

676

677

678

679

680

681

682

683

684

685

686

687

688

689

690

691

692

693

694

695

696

697

698

699

700

701

702

703

704

cytogenetic remissions 118-1205 (median 867) days after HCT. Hallemeier et al. observed graft failure in 5 of 22 evaluable patients given unrelated grafts after conditioning with 5.5 Gy TBI and cyclophosphamide (120 mg/kg) (14). Further efforts for reducing the risk of graft rejection in patients with chronic myeloid leukemia given unrelated HCT are directed at increasing the degree of pretransplant immunosuppression.

\section{Lymphoma and Chronic Lymphocytic Leukemia}

Khouri et al. reported results in 20 patients (median age 51 years) with low-grade NHL given grafts from siblings after conditioning with fludarabine $\left(90-125 \mathrm{mg} / \mathrm{m}^{2}\right.$ ) and cyclophosphamide $\left(2000-2250 \mathrm{mg} / \mathrm{m}^{2}\right)$, with or without added rituximab (15). Postgrafting immunosuppression consisted of tacrolimus and MTX. After a median follow-up of 21 months, the two-year current probability of disease-free survival was $84 \%$. The same authors evaluated the efficacy of nonmyeloablative HCT in 20 patients with NHL recurrence after autologous HCT (48). Ten patients achieved complete remission with salvage chemotherapy before nonablative HCT, eight had a partial response, and two had stable disease. One patient died at 10.5 months from a fungal infection. The three-year progressionfree survival was $95 \%$.

Robinson et al. analyzed data from 188 patients (median age 40 years) with lymphoma [low-grade NHL $(n=52)$, high-grade NHL $(n=62)$, mantle cell lymphoma $(n=22)$, or Hodgkin's disease $(n=52)$ ] given HCT after various reduced-intensity or nonmyeloablative conditioning in EBMT-affiliated centers (49). The one-year probabilities of nonrelapse mortality were $39 \%$ and $22 \%$ in patients older or younger than 50 years, respectively $(p=0.03)$. The twoyear probabilities of overall and progression-free survival were $65 \%$ and $54 \%$ for patients with low-grade NHL, $47 \%$ and $13 \%$ for patients with high-grade NHL, $13 \%$ and $0 \%$ for patients with mantle cell lymphoma, and $56 \%$ and $42 \%$, respectively, for patients with Hodgkin's disease. Chemosensitive disease at HCT was associated with better overall (RR, 2.4; $p=0.002)$ and progressionfree (RR, $2.3 ; p=0.007)$ survivals in multivariate analyses.

Morris et al. reported results of 88 patients with NHL given allogeneic HCT after conditioning with fludarabine $\left(150 \mathrm{mg} / \mathrm{m}^{2}\right)$, melphalan $\left(140 \mathrm{mg} / \mathrm{m}^{2}\right)$, and alemtuzumab (100 mg) (13). Sixty-five patients received PBSC from HLAidentical siblings, while 23 received bone marrow from matched unrelated donors. GVHD prophylaxis consisted of CSP alone. Before DLI, grades III to IV acute GVHD were seen in four patients, but two additional patients developed grade IV acute GVHD after DLI. The actuarial three-year probability of current progression-free survival was $65 \%$ for patients with low-grade lymphoma $(n=41), 50 \%$ for patients with mantle cell lymphoma $(n=10)$, and $34 \%$ for patients with high-grade lymphoma $(n=37)$ (Table 2$)$.

Maris et al. analyzed outcomes of 33 patients with relapsed or refractory mantle cell lymphoma who underwent allogeneic HCT from related $(n=16)$ or 
unrelated $(n=17)$ donors after 2 Gy TBI and fludarabine $\left(90 \mathrm{mg} / \mathrm{m}^{2}\right)(50)$. The overall response rate in the 20 patients with measurable disease at the time of HCT was $85 \%$ (including $75 \%$ complete remissions and $10 \%$ partial remissions) (Fig. 4). The two-year probabilities of relapse, nonrelapse mortality, and progression-free survival were $9 \%, 24 \%$, and $60 \%$, respectively.

Sorror et al. described outcomes in 64 patients with chronic lymphocytic leukemia (median age 56 years) given HCT from HLA-matched related $(n=44)$ or unrelated $(n=20)$ donors after conditioning consisting of 2 Gy TBI with $(n=53)$ or without $(n=11)$ fludarabine $\left(90 \mathrm{mg} / \mathrm{m}^{2}\right)(51)$. Eighty-eight percent of patients were refractory to fludarabine. With a median follow-up of 24 months, the overall response rate was $67 \%$ (including $50 \%$ with complete remission). The two-year rates of nonrelapse mortality, overall, and progressionfree survivals were $22 \%, 60 \%$, and $52 \%$, respectively. Bulky lymphoadenopathy (lymph node diameter $\geq 5 \mathrm{~cm}$ ) independently predicted higher incidence of relapse/progression (HR 3.8, $p=0.009$ ), while marrow infiltration with more than $50 \%$ leukemic cells was associated with worse survival (HR 2.4, $p=0.05$ ). These data, in agreement with those described in smaller series $(52,53)$, show that chronic lymphocytic leukemia is remarkably susceptible to GVT effects.

\section{Multiple Myeloma}

Crawley et al. reported data from 229 patients given allogeneic HCT after various reduced-intensity conditioning in EBMT-affiliated centers (32). One hundred and ninety-two patients received grafts from related donors and 37 from unrelated donors. Overall, $25 \%$ and $48 \%$ of patients achieved complete or partial remissions, respectively. The three-year probabilities of overall and progressionfree survivals were $41 \%$ and $21 \%$, respectively. Adverse progression-free survival was associated with alemtuzumab-containing conditioning (RR 1.8, $p=0.001$ ) and chemoresistance prior to transplant ( $R R$ 2.4, $p=0.0004$ ), suggesting that heavily pretreated patients and those with progressive disease did not benefit from this approach. Chronic GVHD was associated with better progression-free survival $(p<0.0001)$, while grades III to IV acute GVHD was associated with a worse overall survival $(p=0.0007)$ and did not decrease the risk of relapse.

\section{TANDEM AUTOLOGOUS/ALLOGENEIC HCT}

To allow older patients with aggressive chemosensitive disease to benefit from both high-dose chemotherapy and GVT effects, it has been proposed to first use high-dose conditioning and autologous transplantation, which can be administered with overall mortality rates of less than $5 \%$, followed one to three months later by allogeneic HCT using nonmyeloablative conditioning (tandem autologous/allogeneic HCT). This strategy, pioneered by Carella et al. in patients with refractory lymphoma (54), was evaluated by Maloney et al. in 54 patients with 
multiple myeloma. Patients were first given autologous HCT after a cytoreductive dose of $200-\mathrm{mg} / \mathrm{m}^{2}$ melphalan; this was followed 40 to 229 (median 62) days later by allogeneic HCT after 2 Gy TBI (55). Patients were 29 to 71 (median 52 ) years old, and $48 \%$ had refractory (35\%) or relapsed (13\%) disease. Remarkably, the 100-day mortalities after autologous and allogeneic HCT were $2 \%$ each, contrasting with the high nonrelapse mortality (ranging from $20 \%$ to $50 \%$ (56) observed in patients with multiple myeloma given allogeneic HCT after myeloablative conditioning. The two-year overall and progression-free survivals were $78 \%$ and $55 \%$, respectively.

\section{CONCLUSIONS AND CLINICAL PERSPECTIVES FOR THE NEXT FIVE YEARS}

Reduced-intensity conditioning and nonmyeloablative regimens have allowed engraftment of allogeneic hematopoietic cells and the development of GVT effects. Antitumor responses have generally required extended periods of time, with a median time of six months required before achievement of complete remissions. In patients with slowly progressing diseases such as chronic myeloid leukemia in first chronic phase, low-grade myelodysplastic syndrome, chronic lymphocytic leukemia, or low-grade NHL, or with more aggressive diseases in complete remission, nonmyeloablative conditioning may be sufficient to achieve cure of the disease. A number of approaches are being explored for patients with more aggressive diseases, such as acute leukemias, high-grade myelodysplastic syndrome, multiple myeloma, or high-grade lymphomas, who are not in complete remission.

A first approach is to combine nonmyeloablative HCT with "diseasetargeted" therapy, such as monoclonal antibodies or thalidomide. Khouri et al. reported 17 patients with chronic lymphocytic leukemia given allogeneic grafts from related donors after fludarabine $\left(90 \mathrm{mg} / \mathrm{m}^{2}\right)$ and cyclophosphamide $\left(2250 \mathrm{mg} / \mathrm{m}^{2}\right)(53)$. Ten patients received rituximab in addition to chemotherapy. The two-year overall survivals were $100 \%$ and $57 \%$, in patients given or not given rituximab, respectively. We have been studying the administration of I-131 anti-CD45 monoclonal antibody followed by 2 Gy TBI and fludarabine to condition patients with acute myeloid leukemia not in remission and patients with advanced myelodysplastic syndrome (57). This approach has allowed administration of 40 Gy to marrow and 56 Gy to spleen, with a relative sparing of nonhematopoietic organs. Kroger et al. investigated the efficacy of thalidomide $(100 \mathrm{mg})$ combined with DLI in 18 patients with multiple myeloma progressing after reduced-intensity HCT (58). The overall response rate was $67 \%$, including $22 \%$ complete remissions. No grades II to IV acute GVHD were seen, while de novo limited chronic GVHD occurred in two patients (11\%). The twoyear progression-free survival after DLI was $84 \%$.

A second approach might consist of posttransplant infusion of donorspecific cytotoxic T-cells directed against either tumor antigens (such as 
proteinase 3 or Wilms' tumor-suppressor 1 in case of leukemia or patient paraprotein in case of multiple myeloma) or recipient minor histocompatibility antigens expressed exclusively on hematopoietic cells (such as HA-1 and HA-2 minor histocompatibility antigens), potentially increasing antitumoral efficacy of DLI with a low risk of inducing GVHD (59).

A number of prospective phase III studies aimed at better defining the role of nonmyeloablative conditioning in patients with multiple myeloma (BMTCTN 01-02), lymphoma (BMT-CTN 02-02), or acute myeloid leukemia (GOELAMS AML 2001, FHCRC-1992.00) are ongoing in the United States and in Europe. Other randomized studies are focusing on comparing different conditioning regimens (FHCRC-1813.00) or defining the best postgrafting immunosuppression in the nonmyeloablative transplantation setting (FHCRC1938.00).

\section{ACKNOWLEDGMENTS}

We thank Bonnie Larson, Helen Crawford, and Sue Carbonneau for their help with manuscript preparation.

\section{REFERENCES}

1. Storb R. Allogeneic hematopoietic stem cell transplantation: yesterday, today, and tomorrow. Exp Hematol 2003; 31:1-10.

2. Weiden PL, Flournoy N, Thomas ED, et al. Antileukemic effect of graft-versus-host disease in human recipients of allogeneic-marrow grafts. N Engl J Med 1979; 300:1068-1073.

3. Horowitz MM, Gale RP, Sondel PM, et al. Graft-versus-leukemia reactions after bone marrow transplantation. Blood 1990; 75:555-562.

4. Kolb HJ, Schmidt C, Barrett AJ, et al. Graft-versus-leukemia reactions in allogeneic chimeras. Blood 2004; 103:767-776.

5. Barnes DWH, Corp MJ, Loutit JF, et al. Treatment of murine leukaemia with x-rays and homologous bone marrow. Preliminary communication. Br Med J 1956; 2:626-627.

6. Collins RH Jr., Shpilberg O, Drobyski WR, et al. Donor leukocyte infusions in 140 patients with relapsed malignancy after allogeneic bone marrow transplantation. J Clin Oncol 1997; 15:433-444.

7. Bethge WA, Hegenbart U, Stuart MJ, et al. Adoptive immunotherapy with donor lymphocyte infusions after allogeneic hematopoietic cell transplantation following nonmyeloablative conditioning. Blood 2004; 103:790-795.

8. Santos GW, Sensenbrenner LL, Burke PJ, et al. Marrow transplantation in man following cyclophosphamide. Transplant Proc 1971; 3:400-404.

9. Appelbaum FR, Herzig GP, Ziegler JL, et al. Successful engraftment of cryopreserved autologous bone marrow in patients with malignant lymphoma. Blood 1978; 52:85-95.

10. Graw RG Jr., Lohrmann H-P, Bull MI, et al. Bone-marrow transplantation following combination chemotherapy imunosuppression (B.A.C.T.) in patients with acute leukemia. Transplant Proc 1974; 6:349-354. 
11. Or R, Shapira MY, Resnick I, et al. Nonmyeloablative allogeneic stem cell transplantation for the treatment of chronic myeloid leukemia in first chronic phase. Blood 2003; 101:441-445 (comment in Blood 2003; 101(12):5084; author reply 5084-5085; PMID: 12788790).

12. Giralt S, Thall PF, Khouri I, et al. Melphalan and purine analog-containing preparative regimens: reduced-intensity conditioning for patients with hematologic malignancies undergoing allogeneic progenitor cell transplantation. Blood 2001; 97:631-637.

13. Morris E, Thomson K, Craddock C, et al. Outcomes after alemtuzumab-containing reduced-intensity allogeneic transplantation regimen for relapsed and refractory nonHodgkin lymphoma. Blood 2004; 104:3865-3871.

14. Girgis M, Hallemeier C, Blum W, et al. Chimerism and clinical outcomes of 110 unrelated donor bone marrow transplants who underwent conditioning with lowdose, single-exposure total body irradiation and cyclophosphamide. Blood 2005; 105:3035-3041.

15. Khouri IF, Saliba RM, Giralt SA, et al. Nonablative allogeneic hematopoietic transplantation as adoptive immunotherapy for indolent lymphoma: low incidence of toxicity, acute graft-versus-host disease, and treatment-related mortality. Blood 2001; 98:3595-3599.

16. McSweeney PA, Niederwieser D, Shizuru JA, et al. Hematopoietic cell transplantation in older patients with hematologic malignancies: replacing high-dose cytotoxic therapy with graft-versus-tumor effects. Blood 2001; 97 3390-3400.

17. Childs R, Clave E, Contentin N, et al. Engraftment kinetics after nonmyeloablative allogeneic peripheral blood stem cell transplantation: full donor T-cell chimerism precedes alloimmune responses. Blood 1999; 94:3234-3241.

18. Storb RF, Champlin R, Riddell SR, et al. Non-myeloablative transplants for malignant disease. In: Schechter GP, Broudy VC, Williams ME, eds. Hematology 2001: American Society of Hematology Education Program Book. Washington, DC: The American Society of Hematology, 2001:375-391.

19. Baron F, Sandmaier BM. Current status of hematopoietic stem cell transplantation after nonmyeloablative conditioning. Curr Opin Hematol 2005; 12:435-443.

20. Baron F, Maris MB, Sandmaier BM, et al. Graft-versus-tumor effects after allogeneic hematopoietic cell transplantation with nonmyeloablative conditioning. J Clin Oncol 2005; 23:1993-2003.

21. de Lima M, Anagnostopoulos A, Munsell M, et al. Nonablative versus reducedintensity conditioning regimens in the treatment of acute myeloid leukemia and highrisk myelodysplastic syndrome: dose is relevant for long-term disease control after allogeneic hematopoietic stem cell transplantation. Blood 2004; 104:865-872.

22. Storb R, Yu C, Wagner JL, et al. Stable mixed hematopoietic chimerism in DLAidentical littermate dogs given sublethal total body irradiation before and pharmacological immunosuppression after marrow transplantation. Blood 1997; 89:3048-3054.

23. Kerbauy FR, Storb R, Hegenbart U, et al. Hematopoietic cell transplantation from HLA-identical sibling donors after low-dose radiation-based conditioning for treatment of CML. Leukemia 2005; 19:990-997.

24. Sandmaier BM, Maris M, Maloney DG, et al. Low-dose total body irradiation (TBI) conditioning for hematopoietic cell transplants (HCT) from HLA-matched related (MRD) and unrelated (URD) donors for patients with hematologic malignancies: a five-year experience. Blood 2003; 102(pt 1):78a-79a (abstr 264). 
25. Maris MB, Niederwieser D, Sandmaier BM, et al. HLA-matched unrelated donor hematopoietic cell transplantation after nonmyeloablative conditioning for patients with hematologic malignancies. Blood 2003; 102:2021-2030.

26. Ueno NT, Cheng YC, Rondon G, et al. Rapid induction of complete donor chimerism by the use of a reduced-intensity conditioning regimen composed of fludarabine and melphalan in allogeneic stem cell transplantation for metastatic solid tumors. Blood 2003; 102:3829-3836.

27. Baron F, Baker JE, Storb R, et al. Kinetics of engraftment in patients with hematologic malignancies given allogeneic hematopoietic cell transplantation after nonmyeloablative conditioning. Blood 2004; 104:2254-2262.

28. Sandmaier BM, Maloney DG, Maris MB, et al. Conversion of low donor chimerism following nonmyeloablative conditioning for hematopoietic cell transplantation (HCT) using pentostatin and donor lymphocyte infusion (DLI). Blood 2004; 104(pt 1):57a (abstr 186).

29. Mielcarek M, Martin PJ, Leisenring W, et al. Graft-versus-host disease after nonmyeloablative versus conventional hematopoietic stem cell transplantation. Blood 2003; 102:756-762.

30. Sayer HG, Kröger M, Beyer J, et al. Reduced intensity conditioning for allogeneic hematopoietic stem cell transplantation in patients with acute myeloid leukemia: disease status by marrow blasts is the strongest prognostic factor. Bone Marrow Transplant 2003; 31:1089-1095.

31. Michallet AS, Furst S, Le QH, et al. Impact of chimaerism analysis and kinetics on allogeneic haematopoietic stem cell transplantation outcome after conventional and reduced-intensity conditioning regimens. Br J Haematol 2005; 128:676-689.

32. Crawley C, Lalancette M, Szydlo R, et al. Outcomes for reduced-intensity allogeneic transplantation for multiple myeloma: an analysis of prognostic factors from the Chronic Leukemia Working Party of the EBMT. Blood 2005; 105:4532-4539.

33. Weissinger F, Sandmaier BM, Maloney DG, et al. Decreased transfusion requirements for patients receiving nonmyeloablative compared with conventional peripheral blood stem cell transplants from HLA-identical siblings. Blood 2001; 98: 3584-3588.

34. Fukuda T, Hackman RC, Guthrie KA, et al. Risks and outcomes of idiopathic pneumonia syndrome after nonmyeloablative and conventional conditioning regimens for allogeneic hematopoietic stem cell transplantation. Blood 2003; 102: 2777-2785.

35. Hogan WJ, Maris M, Storer B, et al. Hepatic injury after nonmyeloablative conditioning followed by allogeneic hematopoietic cell transplantation: a study of 193 patients. Blood 2004; 103:78-84.

36. Junghanss $\mathrm{C}$, Boeckh M, Carter RA, et al. Incidence and outcome of cytomegalovirus infections following nonmyeloablative compared with myeloablative allogeneic stem cell transplantation, a matched control study. Blood 2002; 99:1978-1985.

37. Junghanss C, Marr KA, Carter RA, et al. Incidence and outcome of bacterial and fungal infections following nonmyeloablative compared with myeloablative allogeneic hematopoietic stem cell transplantation: a matched control study. Biol Blood Marrow Transplant 2002; 8:512-520.

38. Parikh CR, Schrier RW, Storer B, et al. Comparison of ARF after myeloablative and nonmyeloablative hematopoietic cell transplantation. Am J Kidney Dis 2005; 45: 502-509. 
39. Sorror ML, Maris MB, Storer B, et al. Comparing morbidity and mortality of HLAmatched unrelated donor hematopoietic cell transplantation after nonmyeloablative and myeloablative conditioning: influence of pretransplant comorbidities. Blood 2004; 104:961-968.

40. Diaconescu R, Flowers CR, Storer B, et al. Morbidity and mortality with nonmyeloablative compared to myeloablative conditioning before hematopoietic cell transplantation from HLA matched related donors. Blood 2004; 104:1550-1558.

41. Clift RA, Buckner CD, Appelbaum FR, et al. Allogeneic marrow transplantation in patients with acute myeloid leukemia in first remission: A randomized trial of two irradiation regimens. Blood 1990; 76:1867-1871.

42. Clift RA, Buckner CD, Appelbaum FR, et al. Allogeneic marrow transplantation in patients with chronic myeloid leukemia in the chronic phase: A randomized trial of two irradiation regimens. Blood 1991; 77:1660-1665.

43. Alyea EP, Kim HT, Ho V, et al. Comparative outcome of nonmyeloablative and myeloablative allogeneic hematopoietic cell transplantation for patients older than 50 years of age. Blood 2005; 105:1810-1814.

44. Hegenbart U, Niederwieser D, Sandmaier BM, et al. Treatment for acute myelogenous leukemia by low-dose, total-body, irradiation-based conditioning and hematopoietic cell transplantation from related and unrelated donors. J Clin Oncol 2006; 24:444-453.

45. Mohty $\mathrm{M}$, de Lavallade $\mathrm{H}$, Ladaique $\mathrm{P}$, et al. The role of reduced intensity conditioning allogeneic stem cell transplantation in patients with acute myeloid leukemia: a donor $v s$. no donor comparison. Leukemia 2005; 19:916-920.

46. Ho AYL, Pagliuca A, Kenyon M, et al. Reduced-intensity allogeneic hematopoietic stem cell transplantation for myelodysplastic syndrome and acute myeloid leukemia with multilineage dysplasia using fludarabine, busulphan and alemtuzumab (FBC) conditioning. Blood 2004; 104:1616-1623.

47. Baron F, Maris MB, Storer BE, et al. HLA-matched unrelated donor hematopoietic cell transplantation after nonmyeloablative conditioning for patients with chronic myeloid leukemia. Biol Blood Marrow Transplant 2005; 11:272-279.

48. Escalon MP, Champlin RE, Saliba RM, et al. Nonmyeloablative allogeneic hematopoietic transplantation: a promising salvage therapy for patients with non-Hodgkin's lymphoma whose disease has failed a prior autologous transplantation. J Clin Oncol 2004; 22:2419-2423.

49. Robinson SP, Goldstone AH, Mackinnon S, et al. Chemoresistant or aggressive lymphoma predicts for a poor outcome following reduced-intensity allogeneic progenitor cell transplantation: an analysis from the Lymphoma Working Party of the European Group for Blood and Bone Marrow Transplantation. Blood 2002; 100:4310-4316.

50. Maris MB, Sandmaier BM, Storer BE, et al. Allogeneic hematopoietic cell transplantation after fludarabine and 2 Gy total body irradiation for relapsed and refractory mantle cell lymphoma. Blood 2004; 104:3535-3542.

51. Sorror ML, Maris MB, Sandmaier BM, et al. Hematopoietic cell transplantation after nonmyeloablative conditioning for advanced chronic lymphocytic leukemia. J Clin Oncol 2005; 23:3819-3829.

52. Schetelig J, Thiede C, Bornhauser M, et al. Evidence of a graft-versus-leukemia effect in chronic lymphocytic leukemia after reduced-intensity conditioning and allogeneic stem-cell transplantation: the Cooperative German Transplant Study Group. J Clin Oncol 2003; 21:2747-2753. 
53. Khouri IF, Lee MS, Saliba RM, et al. Nonablative allogeneic stem cell transplantation for chronic lymphocytic leukemia: impact of rituximab on immunomodulation and survival. Exp Hematol 2004; 32:28-35.

54. Carella AM, Cavaliere M, Lerma E, et al. Autografting followed by nonmyeloablative immunosuppressive chemotherapy and allogeneic peripheral-blood hematopoietic stem-cell transplantation as treatment of resistant Hodgkin's disease and non-Hodgkin's lymphoma. J Clin Oncol 2000; 18:3918-3924.

55. Maloney DG, Molina AJ, Sahebi F, et al. Allografting with nonmyeloablative conditioning following cytoreductive autografts for the treatment of patients with multiple myeloma. Blood 2003; 102:3447-3454.

56. Bensinger WI. The current status of hematopoietic stem cell transplantation for multiple myeloma. Clin Adv Hematol Oncol 2004; 2:700-706.

57. Pagel JM, Appelbaum FR, Sandmaier BM, et al. ${ }^{131} \mathrm{I}$-anti-CD45 antibody plus fludarabine, low-dose total body irradiation and peripheral blood stem cell infusion for elderly patients with advanced acute myeloid leukemia (AML) or high-risk myelodysplastic syndrome (MDS). Blood 2005; 106(pt 1):119a (abstr 397).

58. Kroger N, Shimoni A, Zagrivnaja M, et al. Low-dose thalidomide and donor lymphocyte infusion as adoptive immunotherapy after allogeneic stem cell transplantation in patients with multiple myeloma. Blood 2004; 104:3361-3363.

59. Bleakley M, Riddell SR. Molecules and mechanisms of the graft-versus-leukaemia effect. Nat Rev Cancer 2004; 4:371-380. 
[pradeepr][6×9-Standard][D:/informa_Publishing/DK0832_Kaspers_112039/z_production/z_3B2_3D_files/978-0-8493-5083-2_CH0024_O.3d] [19/2/08/13:5:56]

[537-561] 


\begin{tabular}{|c|c|c|}
\hline \multicolumn{3}{|c|}{$\begin{array}{l}\text { BOOK: DKO832_Kaspers CHAPTER } 24 \\
\text { TO: CORRESPONDING AUTHOR } \\
\text { AUTHOR QUERIES - TO BE ANSWERED BY THE AUTHOR } \\
\text { The following queries have arisen during the typesetting of your } \\
\text { manuscript. Please answer these queries. }\end{array}$} \\
\hline Q1 & Page: 539 AU: Shortened Running Head title OK? & $\equiv$ \\
\hline Q2 & Page: 543 AU: Expansion for HLA OK? & \\
\hline Q3 & Page: 547 AU: Expansion for CMV OK? & $\equiv$ \\
\hline Q4 & $\begin{array}{l}\text { Page: } 554 \text { AU: Is insert of given in patients given or } \\
\text { rituximab? }\end{array}$ & $\equiv$ \\
\hline Q5 & Page: 539 AU: Sources for Figures 1, 2, 3, and 4 OK & as edited? \\
\hline
\end{tabular}


Chapter: 24

Contributors

\section{Affiliation \\ Address \\ Phone \\ Fax : \\ Email :}

Affiliation

Address

Phone

Fax

EmaiL

Affiliation

Address

Phone

Fax

Email

Contact authors
: ${ }^{1}$ Authors: Frédéric Baron, ${ }^{2}$ Frederick R. Appelbaum and

${ }^{3}$ Brenda M. sandmaier

: 1Fred Hutchinson Cancer Research Center

: 1100 Fairview Ave N, D1-100; PO Box 19024; Seattle, WA 98109-1024

:

$\equiv$

: ${ }^{2}$ Fred Hutchinson Cancer Research Center and the University of Washington,

: 1100 Fairview Ave N, D1-100; PO Box 19024; Seattle, WA 98109-1024

:

:

: fappelba@fhcrc.org

$:{ }^{3}$ Fred Hutchinson Cancer Research Center and the University of Washington,

: 1100 Fairview Ave N, D1-100; PO Box 19024; Seattle, WA 98109-1024

: 206-667-4961

: 206-667-6124

: bsandmai@fhcrc.org

: ${ }^{3}$ Brenda M. andmaier, ${ }^{2}$ Frederick R. Appelbaum 